\title{
O FUTURO DO LEITOR OU O LEITOR DO FUTURO: O LIVRO INFANTIL INTERATIVO E OS LETRAMENTOS MÚLTIPLOS
}

Aline Frederico

\begin{abstract}
RESUMO
Esse artigo explora o livro infantil interativo como forma de expressão literária que exige do leitor infantil orquestrar diversos tipos de letramento para, em última instância, desenvolver sua capacidade de ler criticamente textos multimodais, digitais e interativos diversos. O modelo de análise envolvendo os níveis perceptivo, estrutural e ideológico (SERAFINI, 2010; 2015) é proposto para promover, por meio dos livros digitais, a articulação de múltiplos letramentos na escola.
\end{abstract}

PALAVRAS-CHAVE: livro infantil interativo; letramentos múltiplos; letramento multimodal

\section{Introdução}

uando questionamos o futuro da leitura e a formação de leitores, muitas vezes vislumbramos um futuro utópico em que todas as crianças e jovens estão cercados de textos literários da mais alta qualidade (em geral, clássicos da literatura brasileira e universal), textos que devoram apaixonadamente e que expandem seus conhecimentos e experiência de mundo, promovem uma experiência estética sofisticada ao mesmo tempo que desenvolvem uma visão crítica desses cidadãos em desenvolvimento.

A realidade, no entanto, é bastante diferente. No Brasil, ainda que muito haja melhorado nas últimas décadas, a proporção de bibliotecas públicas por habitante é extremamente baixa, o número de livrarias é pequeno e o preço 
do livro é caro. Na maioria das escolas, a literatura é trabalhada de forma instrumental, e o prazer pela leitura e a liberdade para se escolher o que ler raramente são contemplados. Quando se fala em alfabetização e letramento, o foco ainda é predominantemente a palavra escrita. Ainda que na pré-escola e escola primária os livros ilustrados e histórias em quadrinhos possam estar presentes, eles costumam ser trabalhados em uma pedagogia tradicional, voltada às habilidades de decodificação e compreensão do texto escrito; pouca atenção é dada ao texto visual e às complexas relaçóes entre o texto e a imagem nesses formatos literários.

Fora da escola, no entanto, os alunos se deparam com um complexo mundo comunicacional, em que a televisão e a internet apresentam a palavra escrita em constante e complexa relação com imagens, sons, movimento, gestos. A comunicação humana sempre foi multimodal, mas a palavra escrita por muito tempo foi (e ainda é, na maioria dos casos) privilegiada como a principal linguagem a ser estudada e adquirida (KRESS; VAN LEEUWEN, 2006). O que mudou é que, com a tecnologia digital, a linguagem escrita deixou de ser necessariamente protagonista na comunicação humana, e as outras modalidades semióticas, especialmente a visual, estâo cada vez mais presentes (JEWITT, 2005; KRESS, 2010). Estamos ainda num período de transição marcante do papel, como principal suporte de leitura, para telas (KRESS, 2010), em sua variedade de formatos e características. Segundo Kamantzis e Cope, "novas formas de comunicação e mídia estão redefinindo a forma como usamos a linguagem. Quando as tecnologias de criação de sentido estão mudando tão rapidamente, náo pode haver um conjunto de normas ou habilidades demarcando os limites da alfabetização e do letramento, qualquer que seja o modo como sejam ensinados." (KAMANTZIS \& COPE, 2000, p. 6). Assim, quando falamos em crise da leitura, estamos falando na crise de uma definição tradicional de leitura, em que ler se refere a decodificar e compreender o texto escrito, muitas vezes em mídia impressa. Ainda que essa habilidade seja fundamental e que tenhamos muito a melhorar em termos de alfabetização e letramento tradicionais, ser um leitor hoje em dia requer capacidades e

1 Tradução da autora para original em inglês: "New communication and media are reshaping the way we use language. When technologies of meaning are changing so rapidly, there cannot be one set of standards or skills that constitutes the ends of literacy learning, however thought." 
habilidades que vão muito além e que contemplem a complexidade textual e midiática em que vivemos.

Nunca na história da humanidade os indivíduos foram expostos a tantos textos e a tanta informação e igualmente nunca lhes havia sido dada a capacidade que existe hoje para produzirem textos e informação. Essa capacidade está ao alcance, inclusive, de grande parte das crianças e jovens que criam fotografias, memes, ilustraçóes, pôsteres, banners, vídeos, textos escritos etc., que são disponibilizados na, ou por meio da, internet. Essa produção textual cria o (ou parte do) contexto comunicacional em que vivemos e, ao mesmo tempo, é criada por esse contexto, e os textos estáo limitados às possibilidades (affordances) dos meios utilizados para essa comunicação, numa relação complexa entre a 'langue', o sistema linguístico e a 'parole', a fala ou as enunciaçóes feitas pelos indivíduos (SAUSSURE, 1974), aqui 'langue' sendo entendido mais amplamente como o sistema multimodal de comunicação em que vivemos, e 'parole’ como enunciaçóes multimodais e não unicamente verbais.

Esse complexo sistema, no entanto, passa pouco frequentemente pelas portas da escola nos primeiros anos da educação primária, criando um sério descompasso entre as habilidades que crianças e jovens usam na sua vida cotidiana, e que são fundamentais para seu futuro como adultos (multi-)letrados, e a realidade da sala de aula. Essa complexa e intensa realidade comunicativa muitas vezes é acusada de disputar espaço com a literatura no tempo livre de crianças e jovens, mas a verdade é que, especialmente no Brasil, o espaço da literatura na vida de crianças e jovens sempre foi pequeno e o espaço que a comunicaçáo digital ocupa na vida deles é mais provavelmente o que em outras décadas era ocupado pela televisão. No entanto, diversos autores argumentam que a literatura é material fundamental para o desenvolvimento cognitivo (KÜMMERLING-MEIBAUER \& MEIBAUER, 2013), emocional (NIKOLAJEVA, 2013), estético (KIEFER, 1988; 1995) e linguístico e literário (MEEK, 1982, 1988) na infância. Como, portanto, trazer para a sala de aula o complexo panorama da comunicação digital, explorar novos tipos de letramento que surgem nesse panorama e, ao mesmo tempo, promover a leitura literária de forma atraente e interessante a crianças e jovens?

A proposta desse trabalho é sugerir o livro infantil interativo como uma forma de expressão literária que reflete essa complexa realidade comunicacio- 
nal e que pode ser explorado no contexto educacional, trazendo para a sala de aula, já nos primeiros anos de educação formal, um novo formato literário com potencial para desenvolver leitores em todas suas facetas.

\section{Uma definição mais ampla de "ler": a leitura como construção de signos}

De acordo com a semiótica social multimodal (KRESS, 2010; VAN LEEUWEN, 2015), ler vai muito além de decodificar o texto escrito. Ler é entendido como um processo de cocriação de signos, signos que podem estar apresentados em qualquer modalidade, escrita, visual, sonora, cinética, etc. O leitor, portanto, não é um ser passivo, mas um agente no processo de leitura, que traz consigo uma competência literária, além de uma experiência de vida, interesses e motivaçôes no momento da leitura. $\mathrm{O}$ ato de ler é situado, posicionado num instante único do espaço-tempo. Como resultado, toda releitura é uma nova construção de sentido, pois ainda que parte dos textos seja estática e fixa num suporte, todas as outras variáveis, relacionadas ao leitor e ao contexto sociocultural em que texto e leitor estão situados, mudam.

Entender a leitura como uma criação de signos nos permite repensar a formação do leitor para incorporar, além de textos com o predomínio da linguagem escrita, cada vez mais raros e distantes da realidade contemporânea, textos multimodais. Kress (2010), e Kress e van Leeuwen (2006) argumentam que o texto escrito (um poema, por exemplo) é multimodal, porque se trata da linguagem verbal expressa visualmente, utilizando recursos gráficos como tipografia, tamanho e cor para construir significado. A dinâmica entre linguagem escrita e tipografia foi fortemente explorada na poesia concreta, por exemplo. No entanto, grande parte dos textos impressos a que temos acesso hoje em dia são um conjunto modal (modal ensemble) que articula a linguagem escrita com imagens. No meio impresso, livros didáticos, jornais e revistas são claros exemplos dessa combinação. As histórias em quadrinhos e o livro ilustrado são exemplos de textos literários que exploram essa complexa relação com finalidade poética. Já no meio digital, palavras e imagens podem vir acompanhadas de movimento, som e interatividade, que incorpora os gestos do leitor na construção do texto. Essa combinação está presente em grande 
parte das páginas da internet, como redes sociais, blogs, e sites de notícias. Está fortemente presente também na forma como navegamos e utilizamos dispositivos digitais, como computadores, celulares e tablets, em que os sistemas operacionais e aplicativos se utilizam fortemente dessa dinâmica comunicacional. Em termos literários, além da literatura eletrônica disponibilizada na internet, ainda muitas vezes de forma experimental, os chamados livros-aplicativos interativos têm ganhado espaço especialmente para o público infantojuvenil, explorando as affordances poéticas (SCHWEBS, 2014) do meio digital por meio da multimodalidade e da interatividade. Em 2015, o Prêmio Jabuti, maior prêmio editorial nacional, incluiu pela primeira vez a categoria "Infantil digital”, dando visibilidade a esse tipo de produção e possivelmente estimulando a produção de novos títulos.

\section{O que é o livro infantil interativo?}

O livro infantil interativo é um novo formato de expressão literária voltada ao público infantil que expande as narrativas verbo-visuais características do livro ilustrado impresso ao incorporar sons, movimentos e interatividade. Desde 2010, com o surgimento do iPad, esses livros aparecem principalmente como aplicativos para dispositivos móveis, por exemplo tablets e celulares (por isso também são chamados livros-aplicativos ou book / picturebook apps), tendo suplantado o livro interativo em formato de CD-ROM, cujos acesso e popularidade eram limitados. Diferentemente do CD-ROM, que em geral era rodado em computadores e controlado com o uso de mouse e teclado, dificultando o acesso do leitor infantil, o formato, peso e portabilidade desses dispositivos móveis permite que as narrativas digitais dos livros-aplicativos se aproximem significativamente da experiência de leitura do livro impresso, enquanto a tecnologia touch screen permite uma participação direta do leitor na narrativa, sem o intermédio do mouse (AL-YAQOUT, 2011).

O livro ilustrado, cujo equivalente em inglês é o termo picturebook, é definido pela complexa relação e interdependência entre texto verbal e visual. É diferente do livro com ilustraçôes, em que o texto verbal é prioritário e o visual tem papel decorativo e secundário para a compreensão da narrativa (NIKOLAJEVA; SCOTT, 2011). Lewis (2001) descreveu a dinâmica textual do livro ilustrado como um ecossistema, onde os diferentes signos verbais e visuais que 
compõe a narrativa multimodal formam complexas relações cujo significado do todo é maior que a soma de suas partes. Se um desses elementos é alterado, ocorrem implicaçóes para a narrativa como um todo, por exemplo, quando uma mesma história é ilustrada por um artista diferente, resultando numa nova narrativa verbo-visual. No caso do livro-aplicativo, esse ecossistema é ampliado, e, além das affordances verbais e visuais, essas narrativas ganham novas características e possibilidades de acordo com as affordances das modalidades sonora, cinética e gestual.

A interatividade não é uma modalidade, mas a característica que qualquer texto, impresso ou digital, tem de estabelecer uma relação entre o mundo representado e o mundo real, que inclui o leitor. No meio digital, no entanto, essa relação é mais dinâmica, pois o leitor pode interferir e, por vezes, alterar o mundo representado por meio de duas açóes. Assim, as fronteiras entre o mundo real e o representado não são tão definidas e claras como na maior parte dos textos impressos. Desse modo, essas narrativas permitem a crianças e jovens exercitarem essa relação ativa com textos, que certamente fará parte de sua cultura letrada como adultos, desde o início da sua jornada como leitores. A interatividade possui um aspecto lúdico intrínseco e por isso é muito apreciada pelas crianças, podendo ser um fator importante de motivação e atração ao universo literário a leitores que ainda enfrentam dificuldades no processo de decodificação do texto escrito.

As novas e múltiplas possibilidades de combinação multimodal no livro interativo geram infinitas possibilidades, assim que cada livro apresenta características muito peculiares. Em geral, esses textos são híbridos, porque combinam características de diversas formas narrativas, como o livro ilustrado, o filme de animação e os jogos eletrônicos. Por se tratarem de um aplicativo, ou seja, um software em si mesmo, tecnicamente essas narrativas têm o potencial de explorar todos os recursos do meio digital, porém, o alto custo de produção faz com que, em muitos casos, esses livros se aproximem mais de um livro digitalizado do que de uma narrativa verdadeiramente interativa. Nesse artigo, consideramos especialmente os livros-aplicativos interativos que exploram a potencialidade do meio digital de forma criativa e para além do que era possível no livro impresso. $\mathrm{Na}$ discussão a seguir, alguns exemplos seráo apresentados. 


\section{O livro infantil interativo e alfabetização e letramento tradicionais}

Ainda que hoje as discussóes geralmente se concentrem ao redor do conceito de letramento, ou o domínio "de competências de leitura e de escrita necessárias para a participação em práticas sociais letradas" (SOARES, 2004, p. 7), o processo de alfabetização, ou "aprendizagem do sistema de escrita, ou da tecnologia da escrita” (SOARES, 2004, p. 7) é essencial nos primeiros anos do ensino fundamental. A literatura é uma tradicional aliada no processo de alfabetização, mas o que o livro digital interativo oferece nesse processo além do livro impresso? Em primeiro lugar, o potencial dos livros aplicativos reside no fato de que, em sua maioria, eles apresentam a possibilidade de o leitor acompanhar o texto escrito com a narração desse texto realizada por atores profissionais. O hábito de ler histórias para crianças em voz alta, em casa ou na escola, é fundamental para a aquisição de competência literária (SIPE, 2008), porém prática pouco frequente entre as famílias e escolas brasileiras. A relação entre o som das palavras e a palavra escrita é fundamental nesse primeiro estágio para o desenvolvimento da consciência fonológica e ganha mais significado se realizado de forma contextualizada, como durante a leitura de uma história. Nessas histórias interativas, esse processo de contextualização e criação de significado relacionando sons, palavras escritas e narrativas é ainda intensificado com a presença dos textos visual e auditivo, com efeitos e trilha sonoros. Já a interatividade reforça os aspectos lúdicos da narrativa, presente nos jogos de palavras e sons, nos jogos visuais e em jogos metaficcionais que incluem a participação do leitor na narrativa.

Narrativas como Pequenos grandes contos de verdade (LU, 2015) possuem ainda a funcionalidade que permite ao leitor gravar sua própria narração da história. Um dos aspectos menos positivos da presença de uma narração pré-gravada no aplicativo é que a perda da ligação emocional entre a criança e o coleitor, pai ou professor, aspecto que influi na relação da criança com o texto e com a palavra escrita. Com a função de gravação, no entanto, pais, avós, professores, entre outros, podem gravar leituras personalizadas da história, retomando esse vínculo emocional em momentos em que não podem estar presentes. Em termos de fortalecimento dos processos de alfabetização e de letramento inicial, essa função permite ao leitor iniciante exercitar o caminho inverso, em que ele decodifica o texto escrito e tem um 
registro verbal desse processo. A valorização da produção oral da criança pode ter forte impacto positivo na sua autoestima como leitor. Além disso, a possibilidade de observar esse desenvolvimento e comparar diferentes estágios desse processo pode ser uma ferramenta valiosa para professores no acompanhamento do desenvolvimento leitor dessas crianças e ainda como ferramenta de avaliação.

Variações dessa função, como nos aplicativos Chapeuzinho Vermetho (MASSARANI, 2011a) e Os Três Porquinhos (MASSARANI, 2011b), permitem que as crianças tragam seu repertório literário para contar (e gravar), com suas próprias palavras, histórias clássicas de contos de fadas, apresentadas no aplicativo em uma narrativa visual sem palavras. Aqui, o processo de criação oral de histórias que a criança já domina pode ser explorado como ponto de partida para sua produção escrita, que ainda está em desenvolvimento.

\section{Multiletramentos}

A noção de multiletramento foi proposta em 1996 pelo chamado New London Group, um grupo de acadêmicos dos Estados Unidos, Reino Unido e Austrália que se reuniu em 1994 em New London, Estados Unidos, para discutir novas propostas pedagógicas para o ensino de alfabetização e letramento. Segundo Kalantzis e Cope (2000), a ampliação do conceito de "letramento" para "multiletramentos" tem como objetivo lidar com duas mudanças significativas na realidade do ambiente comunicacional atual: em primeiro lugar, com a multiplicidade de modalidades e meios de comunicação presentes na contemporaneidade, que tem também sido chamado de letramento multimodal; o prefixo multi trata ainda da diversidade cultural e linguística crescentes em um mundo globalizado. Esse último aspecto não será tratado nesse artigo, mas vale lembrar que grande parte dos livros interativos são bi ou multilíngues, em contraste à escassa produção de livros impressos bilíngues para crianças. Além disso, muitos aplicativos produzidos em outros países possuem versão em português, proporcionando aos leitores brasileiros a possibilidade de contato com histórias e culturas diversas. 


\section{O livro infantil interativo e o letramento multimodal}

Baseado em textos multimodais impressos, Serafini define o letramento multimodal como "um processo de geração de significados em interação com textos multimodais, incluindo a linguagem escrita, imagens visuais, e aspectos de design, desde uma variedade de perspectivas, para atender às demandas de um determinado contexto social"2 (SEFAFINI, 2015, p. 413). A literatura infantil pode ser uma importante aliada na promoção do letramento multimodal (UNSWORTH, 2001, SERAFINI, 2015), pois livros ilustrados, histórias em quadrinhos e novelas gráficas de qualidade apresentam complexas relaçóes entre as linguagens verbal e visual, criando efeitos simbólicos, metafóricos e poéticos. Esses textos requerem não apenas a capacidade de ler e compreender os códigos verbais e visuais individualmente, mas ainda compreender como as relaçóes intermodais corroboram ou contestam seus significados individuais na criação de um novo signo multimodal com um significado único (SIPE, 1998).

Nas narrativas digitais, os aspectos verbais, visuais e de design também estão presentes, porém a definição de letramento multimodal para a análise do livro infantil interativo precisa ser expandida para incluir também a leitura e articulação de imagens em movimento, de signos sonoros e da interatividade. No entanto, diferentemente do ensino da linguagem verbal, da alfabetizaçáo ao letramento crítico, que já vêm estruturados ao longo de décadas, como trabalhar o letramento visual, sonoro e digital por meio de livros interativos?

Em primeiro lugar, o letramento multimodal é em sua essência interdisciplinar e pode apresentar uma possibilidade para a integração entre o professor primário e professores de música, de artes visuais e de informática, por exemplo, e que podem trabalhar em conjunto essas habilidades por meio de diferentes disciplinas.

Serafini $(2010 ; 2015)$, baseado na gramática funcional visual (KRESS; VAN LEEUWEN, 2006), propóe um modelo para a análise de livros ilustrados impressos a ser usado em contextos educativos para a promoção do letramento multimodal. Esse modelo está estruturado em três níveis:

2 Tradução da autora para o original em inglês: "Multimodal literacy is a process of generating meanings in transaction with multimodal texts, including written language, visual images, and design features, from a variety of perspectives to meet the requirements of particular social contexts". 
- Perceptivo: nível mais básico de análise, em que o enfoque se dá no sentido literal dos signos. Em termos didáticos, significa olhar em detalhe para os signos que compõe o texto, identificar, elencar e nomear esses elementos.

- Estrutural: nível em que se analisa a gramática funcional das diversas modalidades que compóe o texto, ou como as estruturas das modalidades verbal, visual, sonora, etc., faz com que esses elementos possuam determinados sentidos. Nesse nível, são também consideradas as relações entre as diferentes modalidades ou relaçôes intermodais.

- Ideológico: nível em que são analisados os contextos sociocultural, histórico e político em que esses textos foram criados e em que esses textos são lidos. Essa discussão inclui o processo de criação e distribuição dos textos e a análise crítica das representaçốes presentes nesse texto, abordando questóes raciais, de gênero, distribuição de poder e estereótipos, por exemplo.

A combinação desses diversos níveis de análise tem o objetivo não apenas de tornar os leitores competentes nas diversas linguagens que formam o texto multimodal, mas promover uma leitura crítica das diversas modalidades e do texto multimodal como um todo; afinal, "ser multiletrado não requer apenas a maestria comunicacional, mas a habilidade de analisar criticamente, desconstruir e reconstruir textos variados e outras formas de representação. Também requer a habilidade de se engajar nas responsabilidades sociais e interaçóes associadas a esses textos." ${ }^{3}$ (ANSTEY, 2002, p. 446).

Ainda que o modelo de Serafini seja baseado no texto impresso, ele pode igualmente ser aplicado a textos digitais como os livros interativos, porém a complexidade do texto digital e a falta de experiência de professores em lidar, por exemplo, com os signos sonoros, resultam em um desafio para sua aplicação didática.

3 Tradução da autora para o original em inglês: "Therefore, being multiliterate requires not only the mastery of communication but an ability to critically analyse, deconstruct, and reconstruct a range of texts and other representational forms. It also requires the ability to engage in the social responsibilities and interactions associated with these texts." 
A seguir, será apresentado, de maneira breve, um exemplo baseado na análise de uma cena do livro interativo Quem soltou o pum? (FRANCO; LOLLO, 2011). Nessa história, o menino narrador conta sobre os apuros por que passa quando não consegue segurar o Pum. Enquanto o texto verbal conta sobre os problemas relacionados a soltar o Pum, por exemplo, quando o Pum faz barulho, ou quando uma tia solta o Pum e se faz de desentendida, o texto visual mostra que Pum é, na verdade, o cachorro da família, e a ironia criada no contraponto entre o texto verbal e o visual é responsável pelo efeito humorístico do texto multimodal. $\mathrm{O}$ uso de movimento, interação e sons nesse aplicativo complementam esse sistema de significados, expandindo e intensificando os significados criados pelo texto verbo-visual. Ao final de cada nível de análise, é apresentada uma lista de questóes que o professor pode usar para discussão do texto em sala de aula, guiando os leitores a articular suas habilidades de compreensão e leitura crítica. Essas questóes podem ser facilmente adaptadas para a análise de outros textos, impressos ou digitais.

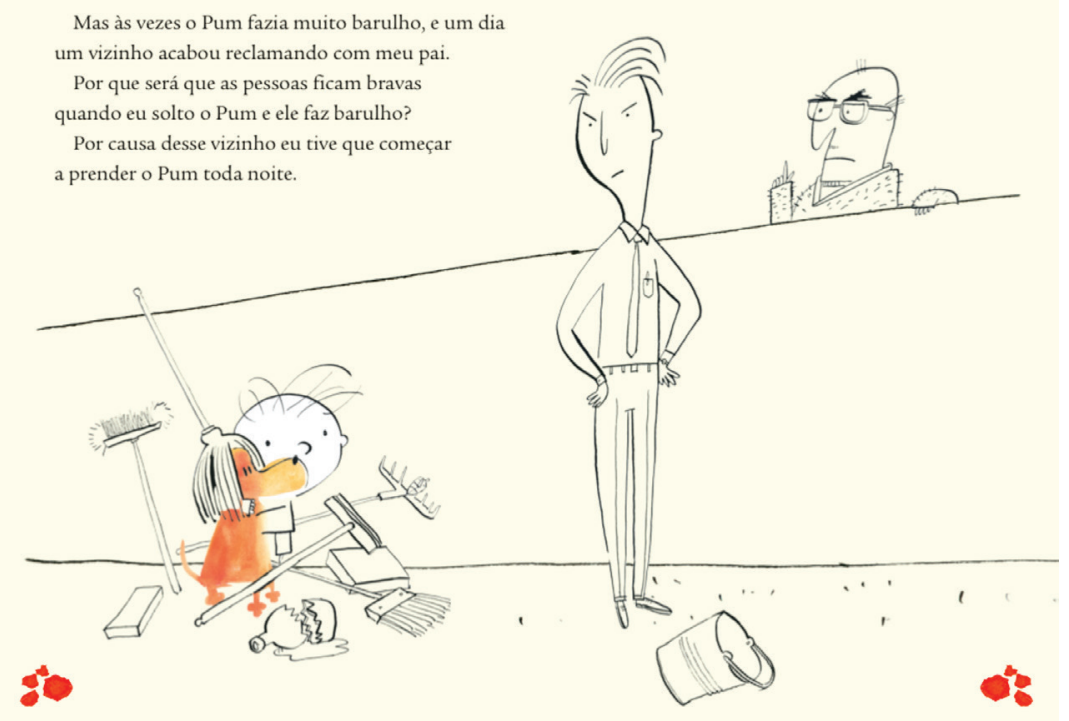

Figura 1: Cena do livro interativo Quem soltou o pum?

(FRANCO; LOLLO, 2011). 


\section{Análise perceptiva}

No nível perceptivo, os leitores devem ser estimulados a explorar o que está imediatamente aparente na narrativa, identificando os signos presentes em cada uma das modalidades usadas na construção da história. Nessa cena, quatro personagens são representados no texto visual: o menino, o cão, o pai e o vizinho. Identificamos o vizinho como tal, porque ele é mencionado no texto verbal e está separado dos demais por um muro. Há também objetos espalhados ao redor do menino e do cão: vassouras, um rodo, um rastelo, uma garrafa quebrada, caixas, um balde.

Apenas dois elementos dessa cena apresentam movimento e são também os mesmos elementos a apresentar som: o balde, que é sensível ao toque, pode ser arrastado pelo leitor e solta um forte e agudo som de metal quando "bate" nos limites da tela; e o vizinho, que mexe o dedo indicador em riste fazendo sinal de "não". Se o leitor toca na tela sobre o vizinho, ele "fala", e ainda que não seja nenhuma língua reconhecível e apenas sons vocais, a entonação e o ritmo claramente podem ser identificados como uma reclamação.

No texto verbal, os mesmos personagens são representados, mas o menino aparece como "eu" e o cachorro não é identificado como tal, mas chamado pelo nome: Pum. O menino fala sobre o problema resultante do barulho produzido pelo Pum: a reclamação do vizinho, que é o aspecto representado no texto visual. Como consequência, o menino conta que passa a prender o Pum, para que não faça mais barulho, mas essa informação está apenas no texto verbal, na cena em questão.

\section{Sugestão de questões para a análise perceptiva:}

- Quais são os elementos presentes nessa cena/história? Quais estão no texto verbal? E no visual? E no sonoro?

- Quais elementos da cena/história apresentam movimento? Quais apresentam som?

- Quais elementos estáo presentes no paratexto (cena de abertura, informação sobre os autores, créditos, e outras informaçóes que acompanham a narrativa principal)? 


\section{Análise estrutural}

Para a análise estrutural do texto, é preciso ir além da descrição das diversas modalidades e de seus significados denotativos e questionar como elas criam essa representação, como interagem para construir a narrativa multimodal e quais os potenciais significados conotativos existentes no texto. Aqui, são exploradas as gramáticas funcionais do texto verbal (HALLIDAY; MATTHIESSEN, 2004) e visual (KRESS; VAN LEEUWEN, 2006), e ainda que o texto sonoro não apresente um sistema preciso com padróes que estabelecem regras de representação e de significado, os signos sonoros têm qualidades perceptivas bastante claras e muitas vezes seus significados são intuitivos (VAN LEEUWEN, 1999). Igualmente é possível, através de um olhar atento ao nível perceptivo, compreender a dinâmica da interatividade na construção de sentido da história. Para esse nível de análise, pode ser necessário introduzir aos leitores uma terminologia, ou metalinguagem, que lhes permita analisar essas características do texto (ARIZPE; STYLES, 2015). Por exemplo, o conceito de saliência (KRESS; VAN LEEUWEN, 2006) se refere ao aspecto do texto visual que possui mais valor destaque (pelo uso de cor, forma, tamanho, etc.), e, portanto, maior valor hierárquico na imagem; outro exemplo são os conceitos de agudo e grave, para descrever os signos sonoros. Para mais ferramentas de análise nesse nível, consultar Serafini $(2010 ; 2015)$ e as gramáticas funcionais das diversas modalidades mencionadas anteriormente.

Nesse exemplo, um aspecto essencial da narrativa diz respeito ao significado da expressão "soltar pum", necessária não apenas para compreender essa cena, mas a narrativa como um todo, e assim experimentar os aspectos lúdico e humorístico do texto literário. $\mathrm{O}$ texto verbal não menciona em nenhum momento que Pum é um cachorro, essa informação está unicamente no texto visual. Em diversas cenas, o texto verbal, se analisado isoladamente, pode ser interpretado como problemas do menino relacionados à flatulência. No entanto, a análise cuidadosa do texto escrito permite perceber que a palavra Pum aparece em letras maiúsculas e, portanto, se trata de um nome próprio. Se o texto está sendo lido em voz alta por outra pessoa ou se a função de narração está sendo utilizada, sem atenção para o texto escrito na tela, essa referência pode passar desapercebida. 
Além da análise da relação entre texto verbal e visual, o texto visual pode também ser analisado em mais profundidade. $\mathrm{O}$ menino e o cachorro são os personagens centrais da história. No texto visual, isso é representado pelo uso da cor. O cachorro é colorido e o menino aparece em branco, enquanto o restante da narrativa é representado com traços pretos sobre um fundo amarelado. $\mathrm{O}$ uso da cor, portanto, atribui saliência a esses dois personagens, atrai o olhar do leitor e sugere que eles são os elementos principais da narrativa.

O barulho que pode ser escutado na história não é o barulho de soltar pum ironicamente sugerido pelo texto verbal - "às vezes o Pum fazia muito barulho" - mas, em alinhamento com o texto visual, o som do balde de metal batendo nos limites da página. Esse som é alto, forte e incômodo, portanto justificando a reclamação do vizinho. A reação e reprovação do vizinho também estão representadas pelo movimento de seu braço, acenando "não" e pelo tom de sua reclamação, ainda que os conteúdos da fala não sejam revelados.

\section{Sugestão de questões para a análise estrutural:}

- O que significa a expressão "soltar pum"? E o que ela significa nessa história? Como sabemos que o significado aqui é diferente?

- Olhando para texto escrito, como podemos saber que Pum não se refere à flatulência, mas a um ser?

- Quais são os personagens principais da história? Como posso identificar esse significado pelo texto visual?

- Qual o significado de cada um dos sons presentes nessa cena?

\section{Análise ideológica}

A análise ideológica é o nível mais complexo de análise e requer a articulação dos elementos presentes no texto com elementos que não estão necessariamente aparentes, como sistemas de poder ou opressão, o contexto histórico em que a obra foi criada e ainda o entendimento do processo de produção e distribuição textuais. Esses aspectos podem ser trabalhados em sala de aula pelo professor antes ou durante a análise do texto. No caso de livros interativos 
digitais, cabe também a análise das diferenças entre textos impressos e digitais e seus diferentes processos de produção e de recepção, habilidades relacionadas ao alfabetismo digital.

A questão da autoria, por exemplo, pode ser discutida no nível ideológico. Para essa discussão, é necessário se levar em conta os elementos paratextuais (que podem, vale dizer, ser analisados em todos os níveis) e, portanto, discutir o texto além da narrativa em si e como as informaçóes paratextuais influenciam a interpretação do texto. Nesse aplicativo, enquanto os autores do texto e da ilustração aparecem na primeira cena do aplicativo, que equivale à capa do livro impresso, portanto posição de grande destaque, e são ainda apresentados em detalhe ao final da narrativa, os criadores da trilha e dos efeitos sonoros aparecem apenas na ficha de créditos. Assim, essas diferentes formas de autoria são valorizadas diferentemente pelo sistema editorial. Nesse caso, os sons no aplicativo são limitados a alguns elementos da narrativa, mas ainda assim são parte dessa narrativa e do que faz esse texto distinto da narrativa impressa. Os alunos podem ainda ser confrontados com a versão impressa do livro para discutir essa e outras diferenças, incluindo as diferentes formas de acesso dos leitores a cada uma das versóes. Quais são as vantagens e desvantagens de textos impressos e digitais? Por exemplo, crianças de nível socioeconômico mais baixo podem não ter um tablet para acessar o livro digital, nem podem acessá-los na maioria das bibliotecas públicas. Por outro lado, uma criança que mora numa cidade que não possui livrarias ou bibliotecas pode se ver impossibilitado de acessar o livro em papel, mas pode potencialmente baixar o aplicativo sem precisar se deslocar. Essas questóes não apenas ampliam as possibilidades de leitura do texto em questão, como estimulam uma reflexão crítica sobre o ambiente comunicacional em que vivemos e suas consequências na vida das pessoas.

Outro aspecto ideológico que pode ser discutido nessa narrativa em particular se refere às relaçóes de poder entre crianças, adultos e animais. Por exemplo, na cena apresentada, a representação visual mostra o pai como autoridade: ele é alto, longilíneo, está posicionado no centro da cena e olha para o menino de cima para baixo, representação da relação entre adulto e criança/ animal que se repete em outras cenas do livro. Já o menino e o cachorro são representados aproximadamente do mesmo tamanho e sugerindo uma relação de igualdade. Além disso, Pum é sempre tratado pelo primeiro nome, 
enquanto o menino e os outros personagens, à exceção da Tia Clotilde, que é tolerante com as travessuras do Pum, não são nomeados. Além do efeito humorístico, essa personalização pode indicar para alguns leitores a humanização do cachorro.

\section{Sugestão de questões para a análise ideológica:}

Aspectos históricos:

- Quando essa história foi criada? Quando se passa a história? Quais aspectos do texto indicam que essa história foi criada e/ou representa esse período? O que você sabe do(s) período(s) em questão?

- Produção e recepção:

- Quem é a provável audiência dessa história? Como podemos inferir que essa seja a audiência? Qualquer criança brasileira pode ler/ter acesso a essa história? Por que sim? Ou por que não?

- Quais as diferenças entre essa história e uma/a versão da história em papel?

- Autoria:

- Quem são os autores dessa história?

- A história são apenas as palavras, ou as imagens também fazem parte dessa história? E os sons?

- Quem criou os sons e as imagens? Onde podemos encontrar essas informaçōes no livro?

- Relaçóes de poder:

- Quais personagens são representados com mais poder, privilégio ou autoridade na narrativa? Que aspectos do texto indicam essas posições?

- Quais são as características (racial, de gênero, etc.) do grupo privilegiado e quais as do grupo menos privilegiado?

- Como essas representaçóes se relacionam com a realidade atual ou com aspectos históricos dessa sociedade?

A análise apresentada acima não é de nenhum modo exaustiva. Essa e qualquer história possuem inúmeros aspectos que podem ser explorados com 
esse modelo de análise. O objetivo aqui é exemplificar, dentro dos limites desse artigo, algumas possibilidades. Essa análise também não pretende ser uma análise definitiva. Um aspecto central da semiótica social multimodal é que textos possuem um potencial de significado, mas esse potencial pode se desenvolver ou não de acordo com os interesses, motivações e experiências do leitor e ainda de acordo com o contexto sociocultural em questão; portanto, os significados não são fixos, mas fluidos.

Finalmente, ainda que a análise ideológica e aspectos da análise estrutural possam parecer complexos para os primeiros anos do ensino fundamental, estudos anteriores indicam que crianças de apenas quatro anos já são capazes de compreender narrativas com conteúdos abstratos e simbólicos complexos (ARIZPE; STYLES, 2015). Cabe ao professor adaptar as perguntas ao nível de seus alunos e a progressivamente desafiá-los com questôes mais complexas. Para discutir os aspectos ideológicos não é necessário em nenhum momento falar diretamente sobre ideologia. Como discutido, a questão de poder e autoridade entre pais e filhos é um tema que faz parte da experiência de vida de crianças de todas as idades.

\section{Considerações finais}

Infelizmente, o acesso aos dispositivos eletrônicos por meio dos quais os livros digitais interativos são distribuídos ainda é limitado no Brasil e praticamente inexistente no sistema público de educação. No entanto, é fundamental que professores tomem conhecimento do imenso potencial desses textos para a promoção da leitura e dos letramentos múltiplos nos primeiros anos do ensino fundamental para que possam reivindicar a presença dessa tecnologia em suas salas de aula.

Um estudo recente no Reino Unido mostra que, ainda que a maior parte das crianças naquele contexto tenha acesso a tablets, o uso é prioritariamente para acesso a vídeos e jogos, sendo o acesso a conteúdo educacional e a literatura ainda bastante limitado (MARSH; PLOWMAN; YAMADA-RICE et al., 2015). Assim, no caso de escolas mais privilegiadas, é importante também dar suporte aos pais sobre os melhores usos dessa tecnologia e sobre como encontrar e utilizar conteúdos de qualidade, especialmente literários. 


\section{Referências}

AL-YAQOUT, Ghada. From Slate to Slate: What does the Future Hold for the Picturebook Series? New Review of Children's Literature and Librarianship, Abingdon, 17.1: 57-77, 2011.

ANSTEY, Michèle. "It's not all black and white": Postmodern picture books and new literacies. Journal of Adolescent \& Adult Literacy, 45.6: 444-57, Malden, EUA, 2002.

ARIZPE, Evelyn; STYLES, Morag. Children Reading Pictures: Interpreting Visual Texts. Londres: RoutledgeFalmer, 2015.

FRANCO, Blandina; LOLLO, José Carlos. Quem soltou o Pum? (livro-aplicativo). Versão 1.2. Companhia das Letras, 2011. Disponível para sistema iOS.

HALLIDAY, M. A. K., \& MATTHIESSEN, C. M. I. M. An introduction to functional grammar. Londres: Edward Arnold, 2004.

JEWITT, Carey. Multimodality, "reading", and "writing" for the $21^{\text {st }}$ century. Discourse: Studies in the Cultural Politics of Education, 26.3: 315-31, 2005.

KALANTZIS, Mary; COPE, Bill. Multiliteracies: Literacy learning and the design of social futures. Londres: Routledge, 2000.

KIEFER, Barbara. Picture books as contexts for literary, aesthetic, and real world understandings. Language Arts, 65.3: 260-71, 1988.

KIEFER, Barbara. The potential of picturebooks: From visual literacy to aesthetic understanding. Englewood Cliffs: Merrill, 1995.

KRESS, Gunther R. Multimodality: A social semiotic approach to contemporary communication. Londres: Routledge, 2010.

.; VAN LEEUWEN, Theo. Reading images: The grammar of visual design. Nova York: Routledge, 2006.

KÜMMERLING-MEIBAUER, Bettina, \& MEIBAUER, Jörg. Towards a cognitive theory of picturebooks. International Research in Children's Literature, 6.2: 143-60, 2013.

LEWIS, David. Reading contemporary picturebooks: Picturing text. Nova York; London: Routledge Falmer, 2001.

LU, Oamal. Pequenos grandes contos de verdade (livro-aplicativo). Versão 1.1. Editora Caixote, 2015. Disponível para sistema iOS. 
MARSH, J.; PLOWMAN, L.; YAMADA-RICE, D.; BISHOP, J.C.; LAHMAR, J., SCOTT, F.; DAVENPORT, A.; DAVIS, S.; FRENCH, K.; PIRAS, M.; THORNHILL, S.; ROBINSON, P; WINTER, P. Exploring play and creativity in pre-schoolers' use of apps: Final project report. TAP: Technology and Play, http://www.techandplay.org, 18/10/2015.

MASSARANI, Mariana. Chapeuzinho vermelho (livro-aplicativo). Versão 1.2. Manati, 2011a. Disponível para sistema iOS.

. Os três porquinhos (livro-aplicativo). Versão 1.2. Manati, 2011b. Disponível para sistema iOS.

MEEK, Margaret. Learning to read. Londres; Toronto: Bodley Head, 1982.

MEEK, Margaret. How texts teach what readers learn. Stroud: Thimble Press, 1988.

NIKOLAJEVA, Maria; SCOTT, Carole. Livro ilustrado: Palavras e imagens. São Paulo: Cosac Naify, 2011.

NIKOLAJEVA, Maria. Picturebooks and emotional literacy. The Reading Teacher, 67.4: 249-54, 2013.

SAUSSURE, Ferdinand de. Course in general linguistics. Londres: HarperCollins, 1974.

SCHWEBS, Ture. Affordances of an app - A reading of The Fantastic Flying Books of Mr. Morris Lessmore. BLFT - Nordic Journal of ChildLit Aesthetics, Elverum, Noruega, 2014, http://www.childlitaesthetics.net/index.php/blft/ article/view/24169, 20/10/2014.

SERAFINI, Frank. Reading multimodal texts: Perceptual, structural and ideological perspectives. Children's Literature in Education, 41.2: 85-104, 2010.

. Multimodal literacy: From theories to practices. Language Arts, 92.6: 412-23, Urbana, USA, 2015.

SIPE, Lawrence. How picture books work: A semiotically framed theory of text-picture relationships. Children's Literature in Education, 29.2: 97-108, 1998.

Storytime: Young Children's Literary Understanding in the Classroom. Nova York: Teachers College Press, 2008.

SOARES, Magda. Letramento e alfabetização: As muitas facetas. Revista Brasileira de Educação, 25: 5-17, Rio de Janeiro, 2004. 
UNSWORTH, Len. Teaching multiliteracies across the curriculum: Changing contexts of text and image in classroom practice. Filadélfia: Open University, 2001.

VAN LEEUWEN, Theo. Speech, music, sound. Nova York: St. Martin's Press, 1999. . Introducing social semiotics. Londres: Routledge, 2005.

\title{
THE FUTURE OF THE READER OR THE READER OF THE FUTURE: CHILDREN'S INTERATIVE BOOKS AND MULTILITERACIES.
}

\begin{abstract}
This work explores the interactive book app for children as a form of literary expression that requires from the young reader the capacity to orchestrate various forms of literacy to promote their ability of reading critically multimodal, digital and interactive texts. Serafini's model for the analysis of picturebooks in three levels, perceptive, structural, and ideological (SERAFINI, 2010; 2015), is proposed as a didactic tool to promote these multiliteracies at school through the reading of picturebook apps.
\end{abstract}

KEYWORDS: picturebook apps; multiliteracies; multimodal literacy

Recebido em: 31/12/2015

Aprovado em: 25/01/2016 